\title{
Effect of age of introduction to an automated milk feeder on calf learning and performance and labor requirements
}

\author{
Catalina Medrano-Galarza, ${ }^{*} \dagger^{1}$ Stephen J. LeBlanc, ${ }^{*} \dagger$ Trevor J. DeVries, $\dagger \ddagger$ Andria Jones-Bitton, ${ }^{*}$ \\ Jeffrey Rushen,§ Anne Marie de Passillé,§ Marcia I. Endres,\# and Derek B. Haley${ }^{*}$ \\ *Department of Population Medicine, Ontario Veterinary College, \\ †Campbell Centre for the Study of Animal Welfare, and \\ ‡Department of Animal Biosciences, Ontario Agricultural College, University of Guelph, Guelph, Ontario, N1G 2W1, Canada \\ §Faculty of Land and Food Systems, University of British Columbia, Agassiz, British Columbia, V6T 1Z4, Canada \\ \#Department of Animal Science, University of Minnesota, St. Paul 55108-6118
}

\section{ABSTRACT}

Group housing of dairy calves with automated milk feeders (AMF) is increasingly being used, but the effect of introducing calves to the AMF at a very young age $(<24 \mathrm{~h})$ on calf performance, health, and welfare, as well as farm personnel labor requirements are unknown. The objective of this controlled trial was to investigate whether early ( $<24 \mathrm{~h}$ after birth) introduction of calves affects the time to learn how to drink from the AMF, labor requirements for feeding milk during the learning phase, and average daily gain during the milk-feeding period compared with calves conventionally introduced at $5 \mathrm{~d}$ of age. Sixty Holstein calves (heifers and bulls) were assigned at birth to either early introduction $(<24$ $\mathrm{h}$ after birth) or conventional introduction (at $5 \mathrm{~d}$ of age) to the group pen with AMF. After birth, calves were housed in individual pens and then introduced, based on assigned treatment, to the group pen with an AMF and a continuous flow stocking approach. Calves were fed milk replacer and gradually weaned from $\mathrm{d}$ 47 to 60 of age. Calves had access to starter from $5 \mathrm{~d}$ of age, and to water and straw right after colostrum feeding. We measured the time between first training to use the AMF and first unassisted visit to the AMF with milk intake, the number of assisted visits until the calf was independent in its use of the AMF (successful learning), and the total time required for milk feeding (labor) until successful learning. Calves were weighed at birth, 30, 46, and $61 \mathrm{~d}$ of age, and were monitored daily for signs of disease. Daily milk and starter intake per calf were automatically recorded. Early-introduced calves took longer to successfully learn to use the AMF $\{64.9 \mathrm{~h}[95 \%$ confidence interval (CI) $=59.1$ to 77.9$]$

\footnotetext{
Received January 4, 2018.

Accepted June 4, 2018.

${ }^{1}$ Corresponding authors: cmedrano@uoguelph.ca and dhaley@ uoguelph.ca
}

vs. $31.4 \mathrm{~h}(95 \% \mathrm{CI}=22.8$ to 47.9$)\}$ and tended to require more assisted visits $[7.8$ visits $(95 \% \mathrm{CI}=6.2$ to 9.7$)$ vs. 5.9 visits $(95 \% \mathrm{CI}=4.8$ to 7.5$)$ ] compared with conventionally introduced calves. Labor for milk feeding was greater for conventionally introduced calves relative to early-introduced calves [145.6 min (95\% CI $=125.1$ to 169.4$)$ vs. $39.9 \mathrm{~min}(95 \% \mathrm{CI}=33.5$ to 47.6$)]$. Disease risk was similar between treatments but the risk of severe versus mild diarrhea was greater for earlycompared with conventionally introduced calves (odds ratio $=4.7 ; 95 \%$ CI 1.01 to 31.1 ). Early-introduced calves consumed less milk during the first days of life compared with conventionally introduced calves $(\mathrm{d} 2=$ 5.5 vs. $6.4 \mathrm{~L}$; d $3=7.0$ vs. $8.2 \mathrm{~L}$; d $4=7.0$ vs. $8.4 \mathrm{~L}$; d $6=6.4$ vs. $7.9 \mathrm{~L} ; \mathrm{d} 7=6.0$ vs. $7.0 \mathrm{~L}$, respectively), with no differences after $8 \mathrm{~d}$. We found no effect of treatment on average daily gain. Although introducing calves $<24 \mathrm{~h}$ after birth required more assistance to use the AMF, farm labor for milk feeding tasks was less for early-introduced calves. Thus, with early introduction to AMF, a trade-off may exist between reduced labor per calf, with no effect on weight gain, but potentially a higher risk of severe diarrhea (vs. mild).

Key words: dairy calf, automated feeding, group housing, introduction

\section{INTRODUCTION}

Labor requirements, calf health and performance, and the adaptation of calves to an automated milk feeder (AMF) are factors influencing the decisions around the age of introduction of calves to the group pen with an AMF. Jensen (2007) found that calves that were introduced at $6 \mathrm{~d}$ old had 2.3 times greater odds of needing guidance to drink from the AMF than calves introduced at $14 \mathrm{~d}$ of age, and spent significantly less time at the feeder and ingested less milk. Fujiwara et al. (2014) found that the more guidance given to a calf to drink from an AMF, the longer it took for that 
calf to drink independently from the feeder. Fujiwara et al. (2014) also showed heavier calves at introduction to the AMF (at $6 \mathrm{~d}$ of age) had a shorter latency to first voluntary drink. Svensson and Liberg (2006) found that the odds of respiratory disease increased as age of introduction to the group pen decreased.

Although research (Svensson and Liberg, 2006; Jensen, 2007) suggests that later introduction (i.e., $>2 \mathrm{wk}$ of age) to the group pen may be preferable in terms of calf health and farm labor, recent data on commercial dairy farms in North America indicate that the median age of introduction to group pens with AMF is $5 \mathrm{~d}$ and ranges from $<1$ to $14 \mathrm{~d}$ (Jorgensen et al., 2017; Medrano-Galarza et al., 2017a; mean group size was 17 calves and ranged from 6 to 60 ). This may stem from producers seeking to minimize the labor required for manually feeding milk to calves when using AMF. In addition, there may be some longer-term advantages of providing calves with social contact at an earlier age (Duve and Jensen, 2011). Currently, insufficient research exists on the implications of introducing very young calves to a group pen with AMF. Therefore, our objectives were to evaluate the effects of early introduction (within $24 \mathrm{~h}$ after birth) to a group pen on calf latency to learn to use the AMF, number of assisted visits until successful learning, ADG, and farm personnel labor requirements regarding milk feeding chores, and compare this early introduction with the average age of introduction in the North America industry. We hypothesized that calves introduced at an early age would take longer to learn to drink from the AMF and need more guidance (i.e., more assisted visits), but would require less labor for feeding milk compared with calves introduced at the conventional age. Additionally, it was hypothesized that age of introduction would not have an effect on ADG.

\section{MATERIALS AND METHODS}

This controlled trial was carried out at the University of Guelph Livestock Research and Innovation Centre Elora Dairy Facility (Elora, ON, Canada) from January 12 (birth date of the first calf enrolled in the study) to July 23, 2017 (1 d after last calf enrolled in the study was weaned). Procedures were reviewed and approved by the University of Guelph Animal Care Committee (AUP no. 3477).

\section{Animals and Treatments}

All calves (bulls and heifers) that were born on the research center were eligible for the study unless other ongoing trials requested animals, which resulted in 11 calves being excluded from the current study. A total of
60 calves were enrolled (30 per treatment group). This sample size would allow for detection of a $24-\mathrm{h}$ (SD = 32 ) difference in the latency to learn to use the AMF, a difference of 3 assisted visits $(\mathrm{SD}=4)$, a 22 -min ( $\mathrm{SD}$ $=30$ ) difference in labor regarding milk feeding tasks, and a $0.15-\mathrm{kg} / \mathrm{d}(\mathrm{SD}=0.2)$ difference in ADG between treatment groups, with $95 \%$ confidence and $80 \%$ power (WINPEPI version 11.62; Abramson, 2011).

Calves were randomly allocated at birth, based on a randomization table (using random number generator in Excel, Microsoft Corp., Redmond, WA), to 1 of the 2 treatments: early introduction $(<24 \mathrm{~h}$ after birth) or conventional introduction (at $5 \mathrm{~d}$ of age) to the group pen with AMF. As calves were born, they were enrolled in the study after their second colostrum feeding. Calves from both treatments were commingled in each pen. Calves were offered $3 \mathrm{~L}$ of their dam's colostrum within $2 \mathrm{~h}$ of birth (or first thing in the morning if the calf was born between 2100 and $0500 \mathrm{~h}$ ), and another $3 \mathrm{~L}$ was provided 6 to $12 \mathrm{~h}$ after the first feeding. The total volume of colostrum consumed varied between calves, mainly dependent on calf size and vigor. Colostrum was always fed through a teat-bottle, unless the calf totally refused to suck, in which case an esophageal tube was used. Calves were allowed to be dried by the dam (first colostrum feeding was usually done in the maternity pen) and separation took place within 2 to $3 \mathrm{~h}$ after birth (except for calves born overnight, where separation occurred between 0500 and $0700 \mathrm{~h}$ ). All calves were placed in an individual pen (described below), where navel disinfection was performed, and vitamin $\mathrm{E}$ and selenium (Dystosel, $1.5 \mathrm{~mL} / 45 \mathrm{~kg}$ of BW s.c.; Zoetis, Kirkland, QC, Canada) and the second colostrum feeding were administered. From January to the end of March, all calves wore a jacket (Calf Jacket, Spectrum Nasco, Newmarket, ON, Canada) for the first 3 wk of life, approximately.

\section{Housing and Management of Pens}

Similar to the most common setup of AMF on commercial dairy farms in Canada (Medrano-Galarza et al., 2017a), 1 AMF was used to deliver milk replacer into 2 feeding stations, each located in a separate pen (group pen 1 and 2; Figure 1). The AMF (DeLaval calf feeder CF1000+, DeLaval Canada, Peterborough, ON, Canada) had an extra pump to allow for the simultaneous feeding of calves in both pens. Although 1 AMF supplied milk to 2 pens, these 2 pens were located in 2 separate nursery rooms (room A and B; Figure 1 ), which were isolated from the cow barn. Two AMF machines were located at the research center, for a total of 4 nursery rooms (Figure 1). The nursery rooms were artificially ventilated through an automatic positive- 
pressure forced-air system. The air coming into the calf nursery rooms came from the attic and from the outdoors.

A continuous flow stocking approach was used (Figure 1). Each nursery room was built to house up to 15 calves. Room A (containing group pen 1 and 5 individual pens assembled within the group pen as needed; Figure 1) was used as the introductory room, where newborns were placed in an individual pen $\left(2.4 \mathrm{~m}^{2}\right.$ lying surface), and then introduced to the group pen 1 based on age, which was determined by the randomly assigned treatment. Calves in individual pens had visual, auditory, and limited physical contact with calves in the group pen and the neighboring individual pens. Group pen 1 housed up to 10 calves $\left(2.8 \mathrm{~m}^{2}\right.$ lying surface per calf $)$ when the 5 individual pens were assembled.

Calves were moved as they aged to group pen 2 (room B) at a mean (SD) age of $26 \pm 8 \mathrm{~d}$; age at movement depended on group size in each pen. Room B was identical to room A (Figure 1), but individual pens were permanently disassembled, which allowed group housing of up to 15 calves $\left(2.8 \mathrm{~m}^{2}\right.$ lying surface per calf). Calves stayed in group pen 2 for at least $1 \mathrm{~d}$, but up to 1 wk after weaning. Heifer calves were then moved to the heifer barn (in the same facility), and bull calves were transported off-site and sold.

The bedding material used in all pens (individual and group) was wood shavings on top of cement flooring. Every day, dirty bedding was removed with a shovel and fresh bedding was added. Once a week, the entire bedding material was removed and replaced. The floor of the milk and grain feeder stalls was washed with water and scrubbed daily.

\section{Milk and Solid Feeding}

Milk. After the second colostrum feeding, all calves were fed milk replacer at a concentration of $150 \mathrm{~g} / \mathrm{L}$ (26\% CP and 18\% crude fat; Excel Pro-Gro, Grober Nutrition, Cambridge, ON, Canada) throughout the entire milk-feeding period. Daily milk allowance was the same in both treatment groups. The feeding method was different between treatment groups for the first $4 \mathrm{~d}$ after colostrum feeding. Calves assigned to the conventional introduction treatment were initially bottle-fed 3 L of milk replacer 3 times/d (at 0630, 1300, and 1800 h) when they were individually housed (start stage), then they were introduced to the group pen with the AMF. Calves assigned to the early introduction treatment were fed through the AMF during the entire milk feeding period; these calves were allowed to drink $9 \mathrm{~L} / \mathrm{d}$ during the first $4 \mathrm{~d}$ in the feeder (maximum of $3 \mathrm{~L}$ per $2 \mathrm{~h}$; start stage). For the next $27 \mathrm{~d}$, starting at $5 \mathrm{~d}$ old (d 5 on the feeder for early-introduced calves, and d 1 for conventionally introduced calves), calves were allowed to drink milk replacer ad libitum from the AMF (maximum of $3 \mathrm{~L}$ per $2 \mathrm{~h}$, for a maximum of $36 \mathrm{~L} / \mathrm{d}$; ad libitum stage). Then, at $32 \mathrm{~d}$ of age, milk allowance was reduced over $5 \mathrm{~d}$ from 12 to $9 \mathrm{~L} / \mathrm{d}$ (step down stage), and remained at $9 \mathrm{~L} / \mathrm{d}$ for the following $10 \mathrm{~d}$ (between 37 and $46 \mathrm{~d}$ of age; plateau stage). Weaning was done gradually over a 14-d period from 9 to $2 \mathrm{~L} / \mathrm{d}$, resulting in calves being completely weaned at $61 \mathrm{~d}$ of age. The AMF were programmed to prepare portions of milk of $0.5 \mathrm{~L}$ at a time.

The AMF were automatically cleaned 3 times/d (mixer cleaning) and a full manual circuit cleaning was performed daily. Automatic calibration for milk replacer was performed 2 times/d, and manual calibration was done at least once a week.

Solid feed. Calves had access to pelleted calf starter (22.2\% CP and 2.4\% crude fat on a DM basis; Floradale Feed Mill Limited, Floradale, ON, Canada) from 5 $\mathrm{d}$ of age. The starter was offered through an automated grain feeder (Figure 1; DeLaval concentrate station, DeLaval Canada) and calves could consume up to 3 $\mathrm{kg} / \mathrm{d}$. Water and chopped wheat straw $(2.5 \mathrm{~cm}$ length) were offered ad libitum in buckets to both treatments from $\mathrm{d} 1$.

\section{Introduction to the Group Pen and Training of Calves to Use the AMF}

Early-introduced calves were moved from the individual pen to the group pen right after the second colostrum feeding and conventionally introduced calves were moved into the group pen right after their last bottle feeding at $5 \mathrm{~d}$ of age. Once calves were introduced to the group, they were left to explore the pen (allowing familiarization with the new environment and pen mates), and were first trained to use the AMF at the next bottle-feeding time (at a mean $\pm \mathrm{SD}$ of 8.7 $\pm 3.5 \mathrm{~h}$ after introduction) unless the calf attended the feeder on its own without needing training. It was possible to determine whether a calf had visited the AMF on its own based on the information provided by the AMF. The AMF displays individual information including milk and starter consumption and time of the last visit of each calf to each feeder.

The training period for each calf started with the first training session and ended when the calf was able to use the AMF independently. A calf was classified as using the AMF independently (successful learning) if it visited the feeder on its own, consumed at least 1 L of milk replacer (which implied that the calf had to stay in the stall and learn to wait for a new portion to be prepared), and did not require further assistance (defined below). 
MEDRANO-GALARZA ET AL.

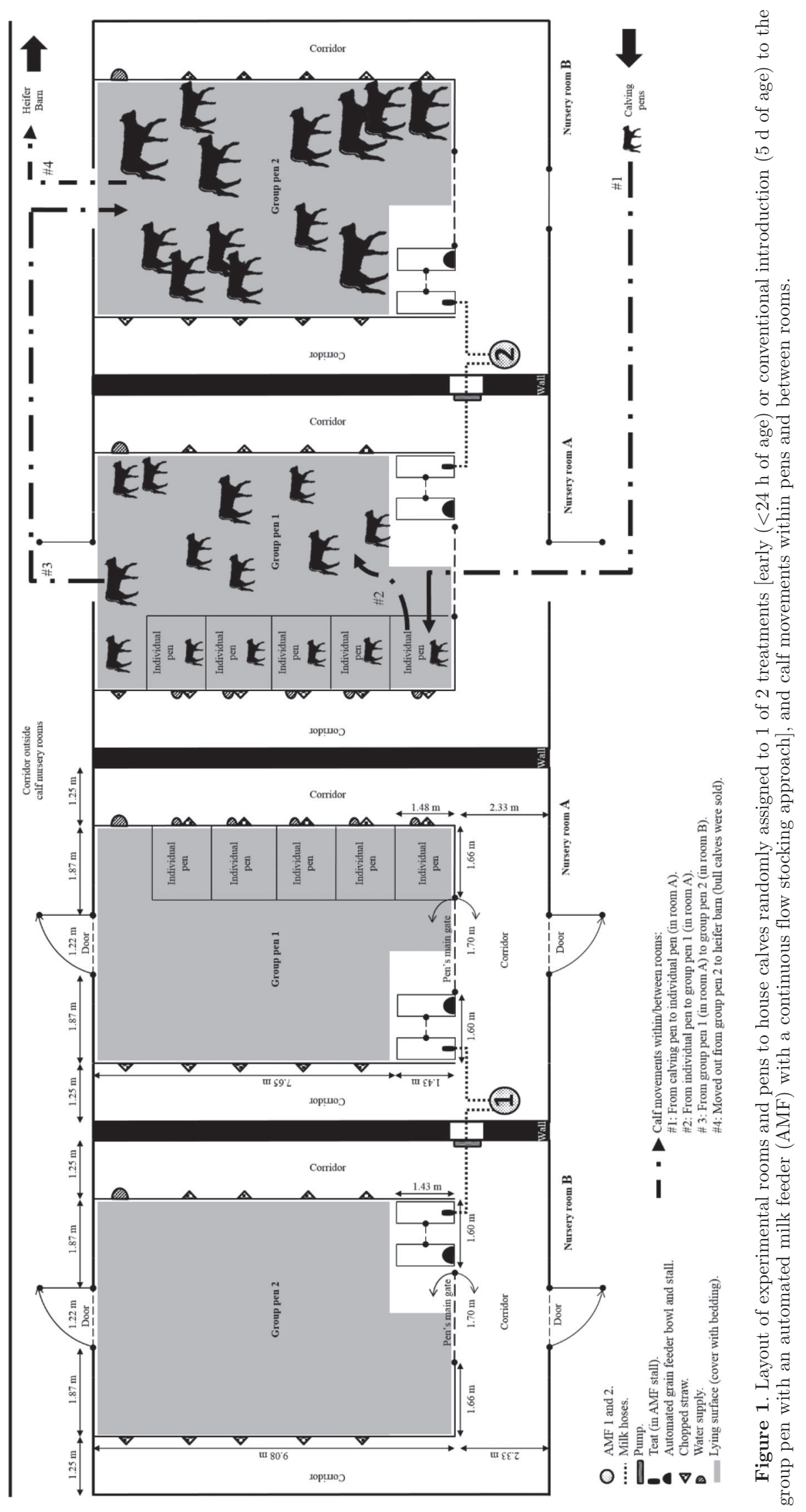


During the first training session, the calf was called or gently pushed into the AMF stall. A rubber strap was put on the back of the stall to avoid the calf stepping out of the stall; the worker then guided the calf's mouth toward the teat using their hands encouraging the calf to suck, and pushed the training button to pump milk into the teat. If the calf started sucking successfully, the worker waited until the calf drank at least $2 \mathrm{~L}$ of milk replacer, then the strap was removed, the worker left, and the calf could finish the meal on its own (up to $3 \mathrm{~L}$ ). The training session was ended after 10 min if a calf refused to suck or when a calf stopped drinking and stood still not willing to drink more. In both cases, the rubber strap was removed and calf was let out of the stall. Once the first training was done, the person training the calves came at every scheduled bottle feeding time $(0630,1300$, and $1800 \mathrm{~h})$ to check if any first-trained calf had successfully learned to use the feeder. If the calf had not drunk on its own since the last assisted visit, the calf was guided to the feeder to drink at every scheduled bottle feeding time until successful learning was achieved. Calves that refused to drink from the AMF and had not consumed milk for $12 \mathrm{~h}$ during the training period were fed $2 \mathrm{~L}$ of milk manually. All calves were trained by the same person (first author).

\section{Data Collection}

Birth weight and BW at 30, 46 (start of weaning), and $61 \mathrm{~d}$ of age were measured using an individual calf scale (1-2-3 animal scale, Bosche $\mathrm{GmbH} \&$ Co. KG, Damme, Germany), and ADG was calculated for these 3 points in time. Birth weight was measured when calves were moved from the calving pen to the nursery room, after first colostrum feeding. A sample of blood from the jugular vein was taken once between 1 and 5 $\mathrm{d}$ of age to measure serum total protein (STP) using a digital refractometer (KS-0050; Kernco Instruments, El Paso, TX).

To assess labor for milk feeding, excluding colostrum feeding, until the calf was totally independent in its use of the AMF (successful learning), we recorded the time (in minutes) spent at each bottle feeding episode (for conventionally introduced calves), which included the time spent preparing the bottle (serving $3 \mathrm{~L}$ of milk replacer into a bottle using the extra portion command in the AMF hand-held terminal) and manually cleaning the bottle, feeding the calf (i.e., holding the bottle for the calf for manual feeding or guiding the calf to the teat-bottle for retraining), and the time spent in each AMF training session (for both early- and conventionally introduced calves). Additionally, the total number of assisted visits to the AMF that each calf needed until successful learning was recorded.

The total amount of time (in hours) between the beginning of first training session and the beginning of the first voluntary (unassisted) visit to the AMF with $>1$ L milk intake (successful learning) was measured to obtain the latency to learn to use the feeder for each calf. At this point the calf was considered as independent and no longer requiring assistance for the following visits. Additionally, we recorded the time of the day each calf was introduced to the group pen and the time of the day when the first training session took place (categories $=$ morning, noon, and evening based on the scheduled bottle feeding time they took place, 0630, 1300, and $1800 \mathrm{~h}$, respectively). The total amount of time (in hours) between introduction to the group and the beginning of the first training and the total amount of milk consumed by each calf during the first voluntary visit to the AMF were also recorded.

Health records were kept daily. Any episode of diarrhea, respiratory disease, navel infection, or other health problem (as described by Windeyer et al., 2014) was recorded, as well as any treatments, relapses, and age of occurrence. A calf was considered sick when it had diarrhea (loose or watery feces; score 2 or 3, respectively, using the fecal score chart developed by McGuirk, 2008) and lost its appetite (i.e., no interest whatsoever in drinking milk). Diarrhea cases were considered mild or severe based on duration of treatment and calf attitude. Depressed calves (not bright/alert) that received oral electrolytes for $>2 \mathrm{~d}$ (Svensson et al., 2003) or received intravenous rehydration therapy (described below) were categorized as having severe diarrhea. A calf was considered to have pneumonia when it had a fever $\left(>39.5^{\circ} \mathrm{C}\right)$ and increased respiratory rate, sound, or effort when breathing.

All sick calves were treated following the instructions provided by the farm veterinarian. Treatment for diarrhea consisted of oral rehydration therapy (CalfLyte II, Vetoquinol N.-A. Inc., Lavaltrie, QC, Canada) twice a day on the day of the onset and subsequently as needed (once or twice a day to ensure that the sick calf was ingesting at least $6 \mathrm{~L}$ of fluids in a day) until milk consumption was back to $6 \mathrm{~L} / \mathrm{d}$ minimum. If the calf did not drink the electrolytes from the bottle, these were administered using an esophageal tube. Meloxicam (Metacam $20 \mathrm{mg} / \mathrm{mL}$ solution, Boehringer Ingelhein, Burlington, ON, Canada) was also administered s.c. at the onset of diarrhea. Intravenous rehydration therapy (electrolyte infusion and physiological saline, Bimeda, MTC Animal Health Inc., Cambridge, ON, Canada) was administered by the farm veterinarian when a calf refused to drink milk replacer or electrolytes vol- 
untarily and dehydration was moderate to severe (calf depressed, sunken eyes, skin tenting $>6 \mathrm{sec}$ ). If a calf was not drinking milk replacer from the AMF (due to illness), milk was manually fed using bottles, alternating with oral electrolytes. If $24 \mathrm{~h}$ passed after last voluntary milk intake, the calf was fed $2 \mathrm{~L}$ of milk replacer using an esophageal tube. Antibiotic therapy was given to calves with diarrhea before $7 \mathrm{~d}$ of age (Borgal 24\%, trimethoprim and sulfadoxine, daily for $3 \mathrm{~d}$, Merck Animal Health, Kirkland, QC, Canada). Treatment for respiratory disease consisted of a single s.c. dose of meloxicam and antibiotic (Nuflor 30\%, florfenicol, Merck Animal Health, or Draxxin 10\%, tulathromycin, Zoetis).

Information regarding calving and colostrum feeding were collected from farm records. The former involved time of birth, which was dichotomized to birth during (from 0430 to $2100 \mathrm{~h}$ ) or outside staff work hours, season of birth (winter, Jan 12 to Mar 21, or spring, Mar 22 to May 24, 2017), and the level of assistance provided during calving (unassisted, easy pull, hard pull, or caesarian section; births outside work hours were classified as unsupervised). Regarding colostrum feeding, we collected information on total volume fed (among the 2 feedings) and method of feeding for each feeding (bottle- vs. tube-fed). Furthermore, we extracted daily milk and starter intake for each calf from the farm computer through the computer program KalbManagerWIN (Förster-Technik GmbH, Engen, Germany).

\section{Data Management and Analysis}

All analyses were performed with SAS version 9.3 (SAS Institute Inc., Cary, NC) using calf as the experimental unit. For the level of assistance during calving, easy pull, hard pull, and caesarean section were grouped into a single category (assisted) due to low numbers of observations, resulting in 3 levels of assistance during calving (assisted, unassisted, and unsupervised). Similarly, for the time of the day when introduced to the group pen, morning and noon were merged, leaving this variable as dichotomous (day vs. evening).

Number of assisted visits, the latency to learn to use the feeder [time interval between the first training session and the first voluntary (unassisted) visit to the AMF with $>1 \mathrm{~L}$ of milk intake], farm labor for milk feeding tasks, and ADG at 30,46, and $61 \mathrm{~d}$ of age were considered as the main dependent variables (outcomes). Daily milk and starter intake, and disease incidence were considered secondary outcomes. The main independent variable of interest for all analysis was treatment (age of introduction: early vs. conventional).
Wilcoxon 2-sample and Pearson chi-squared (or Fisher's exact) tests were used to evaluate differences in baseline variables (i.e., calving- and colostrumrelated factors, sex, birth weight, introduction time, and number of calves in the group pen when a new calf was introduced; Table 1). We found no differences between conventionally and early-introduced calves in any baseline variables except that more calves were tube-fed colostrum in the conventional introduction group (Table 1). As a result, being tube-fed colostrum at least once was included in all multivariable models for effective control of confounding during data analysis as described below (Dohoo et al., 2009).

Linear regression models (PROC MIXED in SAS) were used for the analysis of total labor and ADG at 30, 46, and $61 \mathrm{~d}$ of age. A negative binomial regression model [PROC GENMOD in SAS; used to deal with overdispersion $(\alpha$ or dispersion parameter $=0.196 ; P$ $<0.001$; estimated through Maximum Likelihood-ratio test where $\left.\mathrm{H}_{0}: \alpha=0\right)$ ], was used to analyze the number of assisted visits. To adjust for the effect of pen (linked to an AMF), AMF was included as a fixed effect (Dohoo et al., 2009). Collinearity between 2 variables was considered to be present if their correlation was strong (Pearson and Spearman correlation coefficients $\mathrm{r}>0.7$ ); the least significant variable when tested in the univariable analysis was removed. Independent variables having an association $(P<0.20)$ with the outcome in univariable models were offered to the multivariable model. Treatment was included in all the models regardless of significance. Besides treatment, the initial multivariable model for labor for milk feeding tasks included season of birth, tube feeding colostrum, weight at birth, and STP. The initial multivariable models for ADG at 30, 46, and $61 \mathrm{~d}$ of age included season of birth, sex, tube feeding colostrum, STP, and number of calves in the group pen at the moment of introduction (except for the model of ADG at $61 \mathrm{~d}$ of age), weight at birth (except for the model of ADG at $30 \mathrm{~d}$ of age), latency to learn to use the feeder, and diarrhea (no diarrhea vs. mild vs. severe). The initial multivariable model for the number assisted visits included season of birth, tube feeding colostrum, and weight at birth. A variable was considered a confounder if its removal caused $>20 \%$ change in the estimate of another variable in the model. The model was reduced through backward elimination and variables remained in the model when $P<0.1$. Two-way interactions that involved the main independent variable (age of introduction) were tested and kept if $P<0.1$. Homoscedasticity and normality of residuals were evaluated to assess modeling assumptions for the linear regression models. Homoscedasticity was evaluated graphically by plotting residuals against predicted 
Table 1. Calving- and colostrum-related factors, sex, birth weight, introduction time, and number of calves in the group pen for Holstein calves assigned to conventional introduction ( $5 \mathrm{~d}$ of age) or early introduction ( $<24 \mathrm{~h}$ after birth) to a group pen with an automated milk feeder (AMF)

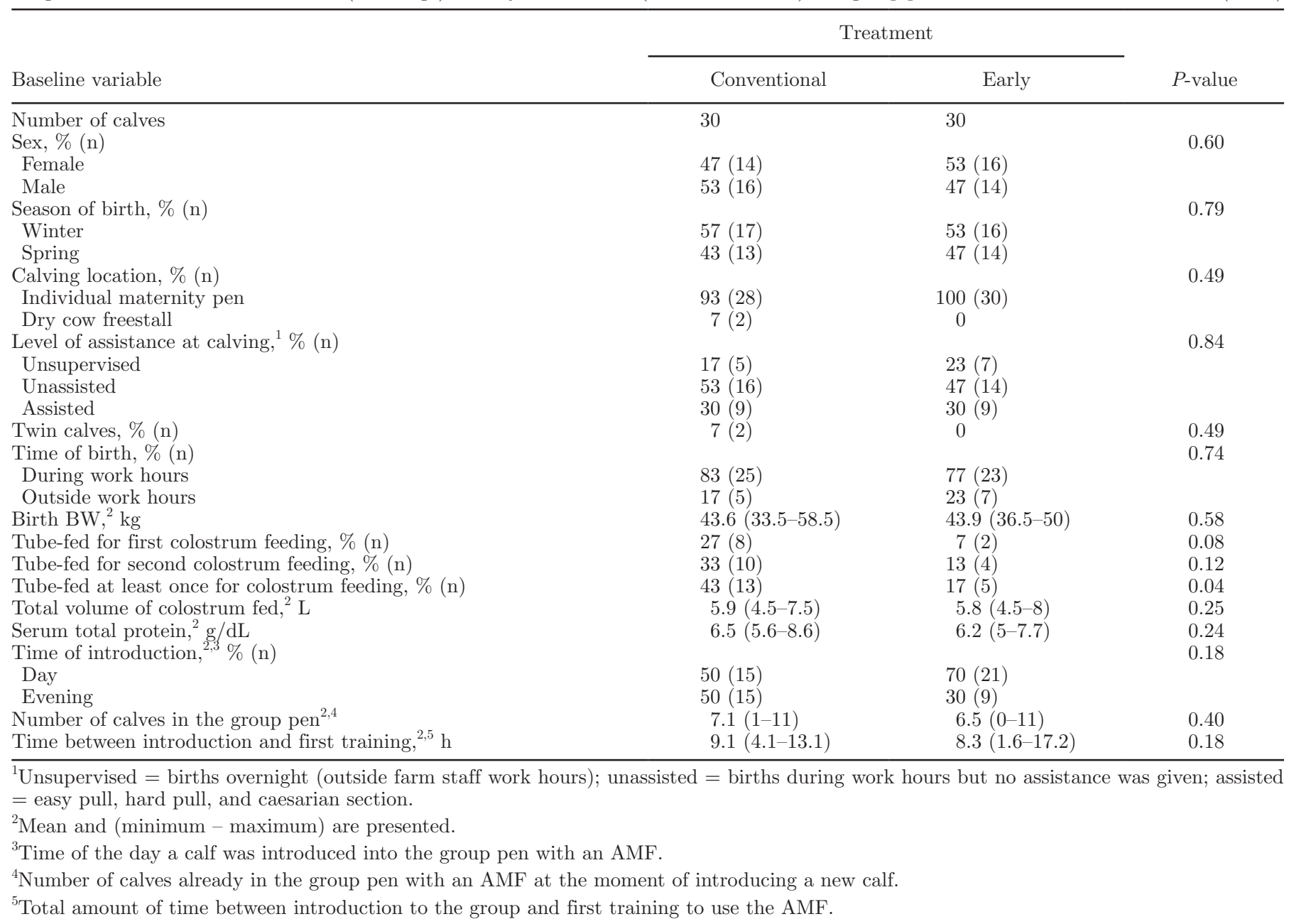

values (Dohoo et al., 2009). Normality was evaluated using normal quantile plots as well as the Shapiro-Wilk test (Dohoo et al., 2009). Log-transformation was used to normalize residuals for labor for milk feeding. Backtransformed least squares means and 95\% confidence intervals are presented. The fit of the negative binomial regression model was evaluated using the Deviance Goodness-of-fit test (SAS, 2017).

Univariable Cox proportional hazards models (PROC PHREG in SAS) were used to screen the effect of covariates (Table 1) on the latency to learn to use the feeder; none were significant and the assumption of proportional hazards was violated for treatment. Therefore, the effect of treatment on the latency to learn to use the feeder was assessed using Kaplan-Meier survival analysis (PROC LIFETEST in SAS). Median survival time and $95 \%$ confidence intervals are presented.

Exact logistic regression models (PROC LOGISTIC in SAS) were used to describe the effect of treatment on the odds of being diagnosed with diarrhea, and specifically with mild or severe diarrhea. The initial models included treatment and tube feeding colostrum as fixed effects. The latter was added for effective control of possible confounding effects, but removed as it was not significant and we observed no confounding effect. The AMF was included as a fixed effect. Kaplan-Meier survival analysis was used to view differences in the time from birth to first diarrhea occurrence by treatment, and the time from introduction to the group to first occurrence of diarrhea. The other disease events had too few occurrences for analysis (pneumonia, $\mathrm{n}=2$; navel infection, $\mathrm{n}=3$; and bloat, $\mathrm{n}=1$ ).

Wilcoxon 2-sample test was used to evaluate differences in milk replacer consumption during the first training session to use the AMF and during the visit when calves successfully learned to use the AMF between treatments. Differences in daily milk replacer and starter intake during the milk feeding period (60 
d) between early- and conventionally introduced calves were evaluated using linear regression models (PROC MIXED in SAS). The models included the fixed effects of calf age, treatment, and the interaction between time (age) and treatment, and the random effect of calf within treatment to adjust for the correlation between repeated observations of individual calves. To adjust for the effect of pen (linked to an AMF), AMF was included as a fixed effect (Dohoo et al., 2009). The variance-covariance matrix used an autoregressive structure. Homoscedasticity and normality of residuals were evaluated graphically to assess modeling assumptions.

Each variable had 60 observations; however, data regarding milk and starter intake and ADG were incomplete because 3 calves died before the end of the trial. Two early-introduced calves' deaths were associated with calf diarrhea and septicemia (at $10 \mathrm{~d}$ of age) and cecal infarction (postmortem diagnosis; calf was euthanized at $9 \mathrm{~d}$ of age). One conventionally introduced calf was removed from the herd due to a clinically diagnosed heart murmur (at $34 \mathrm{~d}$ of age). Removal of data from these 3 calves for the other outcomes did not affect the models, thus we chose to retain them.

\section{RESULTS}

Calves were enrolled in the study at a mean $( \pm \mathrm{SD})$ rate of $3.1 \pm 1.7$ calves per week. The weekly mean group size for group pens 1 (introductory group pens) was $7.3 \pm 2.7$ calves per group and the weekly mean group size for group pens 2 was $12 \pm 4.1$ calves per group. The weekly mean age range between calves housed in group pens 1 was $15.5 \pm 11.01 \mathrm{~d}$, and for group pens 2 it was $22.5 \pm 10.7 \mathrm{~d}$. The following results are described based on the biological order of events.

\section{Learning to Use the AMF}

During training to use the AMF, $6.7 \%$ of calves (1 early-introduced calf and 3 conventionally introduced calves) had to be fed manually at least once because had not consumed milk from the AMF for $12 \mathrm{~h}$. Only 1 calf (conventionally introduced) drank milk from the AMF on its own without requiring training.

In multivariable analysis, the number of assisted visits to the AMF until successful learning tended to be greater $(\mathrm{df}=56 ;$ Wald chi-squared $=2.81 ; P=0.09)$ for early-introduced calves (LSM $=7.8$ assisted visits; $95 \% \mathrm{CI}=6.2$ to 9.7$)$ than conventionally introduced calves (5.9 assisted visits; $95 \% \mathrm{CI}=4.8$ to 7.5 ). Birth weight also tended to be associated with the number of assisted visits $(\mathrm{df}=56$; Wald chi-squared $=3.18 ; P$
$=0.07)$ to the AMF, where for every kilogram of birth weight increase, the odds of an assisted visit decreased 0.96 times $(95 \% \mathrm{CI}=0.93$ to 1$)$.

Age of introduction was associated with the latency to learn to use the feeder, with differences occurring earlier (Wilcoxon test: $\mathrm{df}=1$; chi-squared $=9.38 ; P$ $=0.002)$ rather than later ( $\log$ rank test: $\mathrm{df}=1$; chisquared $=1.37 ; P=0.24$ ) in the time period studied (Figure 2). When introduced to the group pen before $24 \mathrm{~h}$ of age, calves took longer to successfully learn to use the AMF (median $=64.9 \mathrm{~h} ; 95 \% \mathrm{CI}=59.1$ to $77.9 \mathrm{~h}$ ) compared with calves introduced at $5 \mathrm{~d}$ of age $($ median $=31.4 \mathrm{~h} ; 95 \% \mathrm{CI}=22.8$ to $47.9 \mathrm{~h})$.

\section{Labor for Milk Feeding Tasks}

In multivariable analysis, farm labor for milk feeding tasks after colostrum until calves successfully learned to use the AMF was greater $(\mathrm{df}=55 ; t$-value $=12.8$; $P<0.001)$ for calves introduced to the group at $5 \mathrm{~d}$ of age $(\mathrm{LSM}=145.6 \mathrm{~min} ; 95 \% \mathrm{CI}=125.1$ to $169.4 \mathrm{~min})$ compared with calves introduced before $24 \mathrm{~h}$ of age (39.9 $\mathrm{min} ; 95 \% \mathrm{CI}=33.5$ to $47.6 \mathrm{~min})$. Calves born in the winter $(88.9 \mathrm{~min} ; 95 \% \mathrm{CI}=77.8$ to $101.7 \mathrm{~min}$ ) required more farm personnel labor than calves born in the spring ( $65.3 \mathrm{~min}$; $95 \% \mathrm{CI}=53.1$ to $80.4 \mathrm{~min}$; $\mathrm{df}=55 ; t$-value $=-2.64 ; P=0.01)$. Calves that were tube-fed colostrum at least once tended to require more labor than calves that voluntarily consumed colostrum [84.3 $\mathrm{min}$ ( $95 \% \mathrm{CI}=68.8$ to $103.3 \mathrm{~min})$ vs. $68.9 \mathrm{~min}$ $(95 \% \mathrm{CI}=60.4$ to 78.6$)$, respectively; $\mathrm{df}=55 ; t$-value $=-1.81 ; P=0.07]$.

\section{Calf Health}

Overall, $82 \%(\mathrm{n}=49)$ of all calves enrolled in the study had an episode of diarrhea, of which $71 \%$ of the cases were mild. Mild diarrhea occurred in $50(\mathrm{n}=15)$ and $67 \%(\mathrm{n}=20)$ of early- and conventionally introduced calves, respectively. Severe diarrhea occurred in $37(\mathrm{n}=11)$ and $10 \%(\mathrm{n}=3)$ of early- and conventionally introduced calves, respectively. Calves with severe diarrhea received treatment for a mean of $5.7 \pm 1.8$ d. Three calves in the early-introduced group had a diarrhea relapse, whereas no conventionally introduced calves had a diarrhea relapse.

In the exact logistic regression, the odds of having diarrhea or having mild diarrhea versus not having diarrhea did not differ between treatments (Table 2). Among calves with diarrhea, the risk of having severe versus mild diarrhea was higher for early-introduced calves compared with conventionally introduced calves (Table 2). Early-introduced calves had onset of diar- 


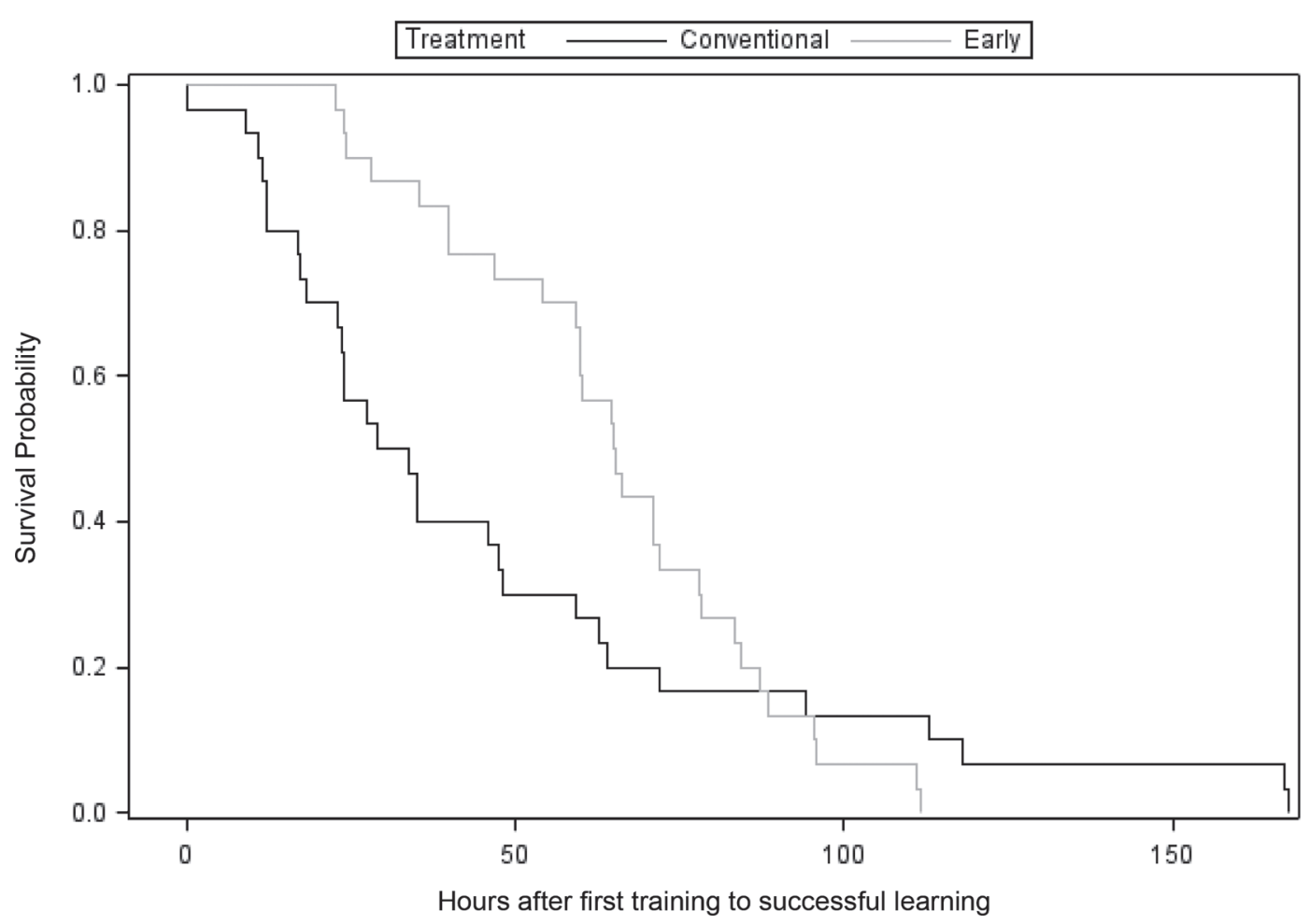

Figure 2. Kaplan-Meier survival analysis graph, with time interval (in hours) between the first training session to use the automated milk feeder (AMF) and the first voluntary (unassisted) visit to the AMF with $>1 \mathrm{~L}$ of milk intake, indicative of successful learning) for the 60 calves randomly assigned to early ( $<24 \mathrm{~h}$ of age) or conventional introduction ( $5 \mathrm{~d}$ of age) to the group pen with an AMF. Wilcoxon test: $P=0.002$; Log Rank test: $P=0.24$

rhea at a younger age $($ median $=6 \mathrm{~d} ; 95 \% \mathrm{CI}=5$ to 7 d) compared with calves introduced at $5 \mathrm{~d}$ old (median $=10 \mathrm{~d}, 95 \% \mathrm{CI}=8$ to $13 \mathrm{~d}$; Wilcoxon test $P=0.001$; $\log$ rank test $P=0.002$ ). However, the time from introduction to the group pen to the onset of diarrhea did not differ between treatments (median for early introduction was $6 \mathrm{~d}, 95 \% \mathrm{CI}=5$ to $7 \mathrm{~d}$; conventional introduction was $6 \mathrm{~d}, 95 \% \mathrm{CI}=4$ to $9 \mathrm{~d}$; Wilcoxon test $P=0.53 ;$ Log rank test $P=0.31$ ).

\section{Milk and Starter Intake}

Overall, milk replacer consumed during the first training session to use the AMF differed between treatments $(\mathrm{df}=1$; chi-squared $=27.49 ; P<0.001)$. Early-introduced calves consumed $1.2 \pm 0.9 \mathrm{~L}$, whereas conventionally introduced calves consumed $2.6 \pm 0.8 \mathrm{~L}$. On the other hand, milk consumption during the visit when calves successfully learned to use the AMF did

Table 2. Univariable exact logistic regression models describing the effect of introduction to the group pen with an automated milk feeder $<24$ $\mathrm{h}$ after birth (early) or at $5 \mathrm{~d}$ old (conventional) on the risk of having diarrhea at least once $<60 \mathrm{~d}$ of age

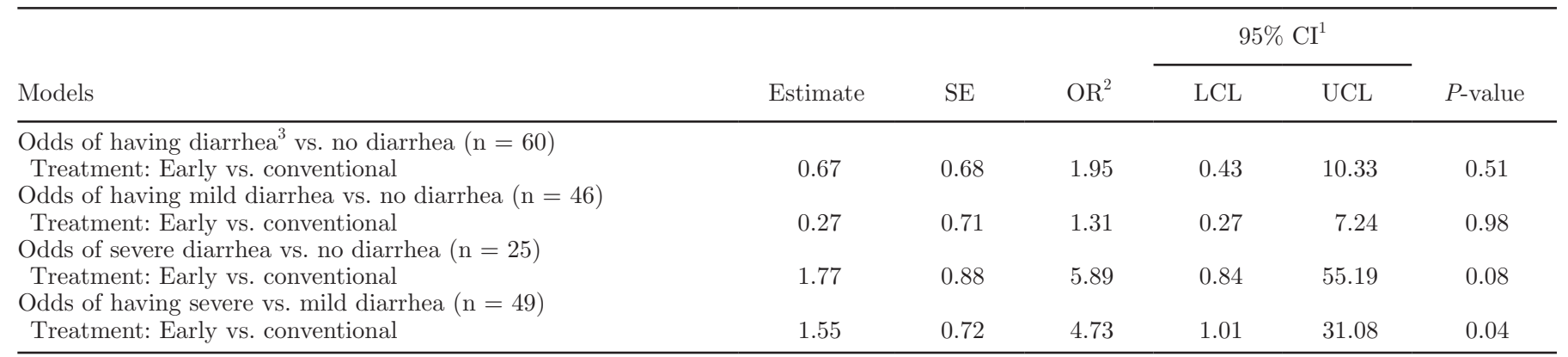

${ }^{1}$ Confidence interval for the odds ratio, lower confidence limit (LCL), and upper confidence limit (UCL).

${ }^{2}$ Odds ratio.

${ }^{3}$ All diarrhea cases (mild or severe). 


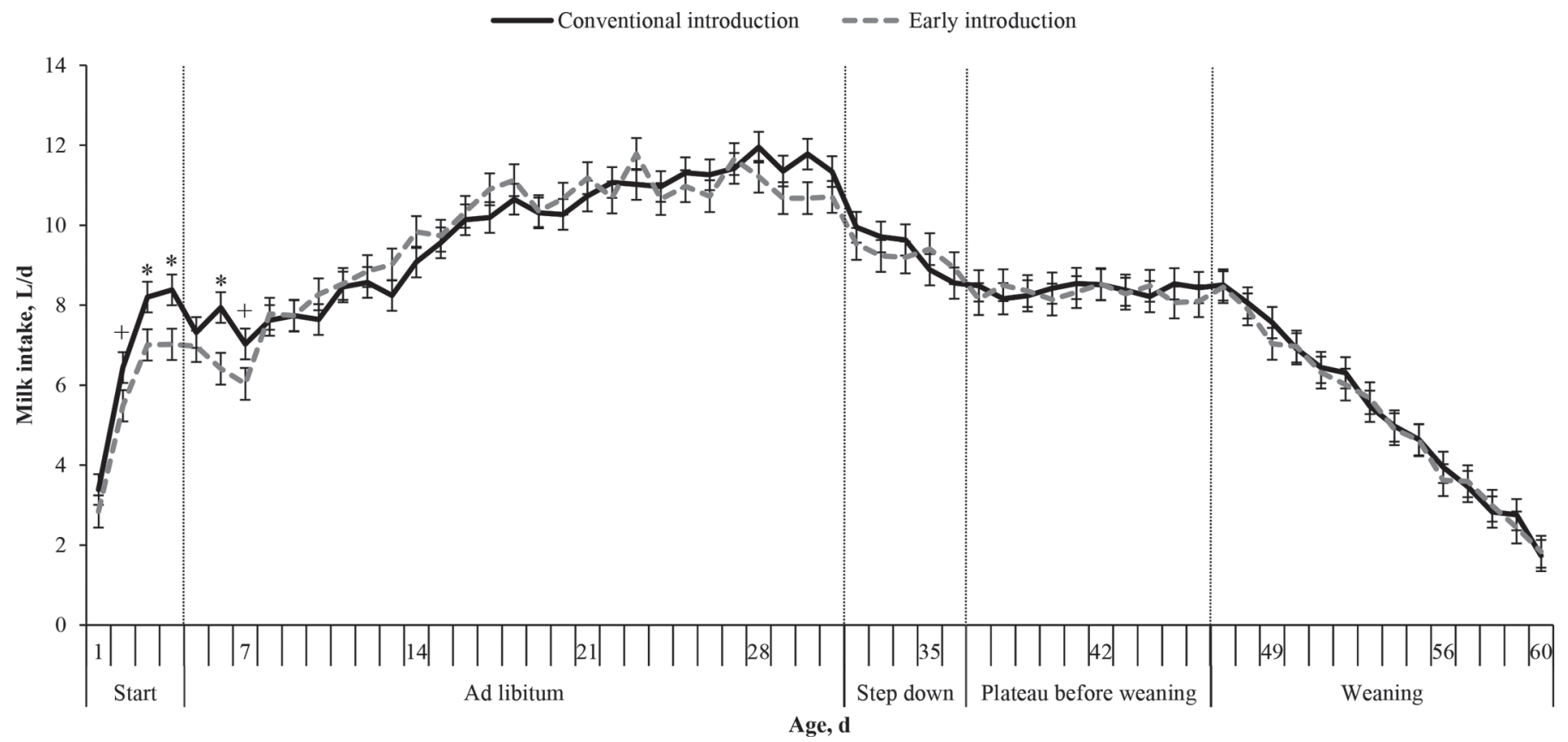

Figure 3. Mean daily milk intake ( $\pm \mathrm{SE}$ ) across the 5 stages of the milk feeding period (from 1 to $60 \mathrm{~d}$ of age) for 60 calves introduced to a group with an automated milk feeder at $5 \mathrm{~d}$ of age (conventional introduction) and before $24 \mathrm{~h}$ of age (early introduction). Milk allowance for each milk feeding stage: start $=9 \mathrm{~L} / \mathrm{d}$; ad libitum $=$ up to $36 \mathrm{~L} / \mathrm{d}$; step down period = gradual reduction from 12 to $9 \mathrm{~L} / \mathrm{d}$; plateau before weaning $=9 \mathrm{~L} / \mathrm{d}$; and weaning $=$ gradual reduction from 9 to $2 \mathrm{~L} / \mathrm{d} .{ }^{*} P<0.05,{ }^{+} P<0.1$.

not differ between treatments (early introduction $=2.6$ $\pm 0.6 \mathrm{~L}$; conventional introduction $=2.6 \pm 0.5 ; \mathrm{df}=1$; chi-squared $=0.048 ; P=0.83$ ).

In multivariable analysis, early-introduced calves consumed less milk compared with conventionally introduced calves during the first $7 \mathrm{~d}$ of life, with no differences thereafter (Figure 3). We found no differences in the total amount of milk replacer consumed from birth to $1 \mathrm{~d}$ before starting weaning (early introduction $=417.7 \pm 54.9 \mathrm{~L}$; conventional introduction $=425.7 \pm$ $56.9 \mathrm{~L} ; \mathrm{df}=1$; chi-squared $=0.33 ; P=0.56$ ).

We observed no differences in the starter intake between treatments. Overall, daily mean (LSM) starter intake among both treatments by each stage of the milk feeding period where access to grain was allowed and weaning period were $0.04 \mathrm{~kg} / \mathrm{d}$ for ad libitum $(95 \%$ CI $=0$ to $0.11 \mathrm{~kg} / \mathrm{d}), 0.17 \mathrm{~kg} / \mathrm{d}$ for step down $(95 \% \mathrm{CI}=$ 0.10 to $0.25 \mathrm{~kg} / \mathrm{d}), 0.37 \mathrm{~kg}$ for plateau $(95 \% \mathrm{CI}=0.29$ to $0.44 \mathrm{~kg} / \mathrm{d}), 0.97 \mathrm{~kg} / \mathrm{d}$ for first week of weaning pe$\operatorname{riod}(95 \% \mathrm{CI}=0.90$ to $1.04 \mathrm{~kg} / \mathrm{d})$, and $2.0 \mathrm{~kg} / \mathrm{d}$ for last week of weaning period $(95 \% \mathrm{CI}=1.92$ to $2.1 \mathrm{~kg} / \mathrm{d})$.

\section{ADG}

In the multivariable analysis, we noted no effect of treatment on the ADG at $30 \mathrm{~d}$ [early- vs. conventionally introduced calves, LSM (95\% CI), 0.92 (0.83 to
$1.02)$ vs. $0.88 \mathrm{~kg} / \mathrm{d}$ (0.81 to 0.96$)$, respectively, $\mathrm{df}=$ $50 ; t$-value $=-0.89 ; P=0.38]$, at $46 \mathrm{~d}[0.94$ (0.88 to $0.99)$ vs. $0.90 \mathrm{~kg} / \mathrm{d}(0.85$ to 0.95$) ; \mathrm{df}=49 ; t$-value $=$ $-1.30 ; P=0.21]$, or at $61 \mathrm{~d}[0.96(0.91$ to 1.01$)$ vs. $0.93 \mathrm{~kg} / \mathrm{d}(0.88$ to 0.97$) ; \mathrm{df}=50 ; t$-value $=-1.11 ; P$ $=0.27$ of age. The ADG was influenced by sex, season of birth, and diarrhea. Female calves [LSM (95\% CI) $=0.88 \mathrm{~kg} / \mathrm{d}(0.83$ to 0.93$)$ ADG at $61 \mathrm{~d}$; results at 30 and $46 \mathrm{~d}$ are not shown but were similar], calves born in the spring $[0.89 \mathrm{~kg} / \mathrm{d}(0.83$ to 0.96$)]$, or calves that had severe diarrhea $[0.84 \mathrm{~kg} / \mathrm{d}(0.79$ to 0.90$)]$ had a lower ADG at $61 \mathrm{~d}$ of age compared with male calves $[1.0 \mathrm{~kg} / \mathrm{d}(0.95$ to 1.04$) ; \mathrm{df}=50 ; t$-value $=-4.36 ; P$ $<0.001]$, calves born in the winter $[0.98 \mathrm{~kg} / \mathrm{d}(0.95$ to $1.02) ; \mathrm{df}=50 ; t$-value $=-2.66 ; P=0.01]$, or calves that did not have diarrhea $[0.97 \mathrm{~kg} / \mathrm{d}(0.89$ to 1.05$)$; df $=50 ; t$-value $=-2.65 ; P=0.01]$, respectively. Only up to $30 \mathrm{~d}$ of age, a 1-h increase in the latency to learn to use the AMF was associated with $0.001 \mathrm{~kg} / \mathrm{d}(\mathrm{SE}=$ $0.0007 \mathrm{~kg} / \mathrm{d})$ lower ADG $(\mathrm{df}=50 ; t$-value $=-2.12 ; P$ $=0.03)$.

\section{DISCUSSION}

Many dairy producers prefer to introduce calves to an AMF as soon as possible (Jorgensen et al., 2017; Medrano-Galarza et al., 2017a) without clear evidence 
to inform the decision about the timing of introduction. Our study is the first to provide information on the effects on learning, performance, and farm personnel labor of introducing calves to a group pen with AMF within $24 \mathrm{~h}$ after birth. The results demonstrate that, under housing conditions reflecting common practice on commercial farms, early introduction of calves was associated with a reduced labor for milk feeding tasks, despite the longer latency to learn to use the AMF, and had no effects on ADG to $61 \mathrm{~d}$. Although age of introduction did not affect the odds of a calf having diarrhea (onset occurred $6 \mathrm{~d}$ after introduction to the group pen in both groups), early-introduced calves experienced higher odds of severe diarrhea (vs. mild diarrhea) at a younger age. We encourage larger-scale studies on multiple farms to confirm these effects.

Once calves were introduced to the group pen with the AMF, we found that early-introduced calves took longer to learn to use the AMF ( 65 vs. $31 \mathrm{~h}$ ) and tended to require more assistance to use the feeder (7.8 vs. 5.9 assisted visits) until successful learning was achieved compared with conventionally introduced calves. Similarly, Jensen (2007) found that younger calves (although introduced at $6 \mathrm{~d}$ of age) required guidance for $48 \mathrm{~h}$, whereas calves introduced at $14 \mathrm{~d}$ of age only required guidance for $24 \mathrm{~h}$. Fujiwara et al. (2014) also found that heavier 6-d-old calves (at introduction to the group pen) had a shorter latency to the first voluntary milk intake from the AMF. Although they introduced all their calves at a same age and examined the effects of their weight at introduction on the latency to learn, we could infer that a 5-d-old calf would be expected to weigh more than a $<1$-d-old calf, thus it would have a shorter latency to learn to use the AMF.

In the present study, we did not find an effect of group size on the latency to learn to use the AMF. The weekly mean group size of the introductory pens (group pens 1) was 7.3 calves, whereas in the majority of commercial farms in Canada use group sizes of 10 to 15 calves (Medrano-Galarza et al., 2017a) and in the Midwestern United States the average is 17 calves (Jorgensen et al., 2017). Large group size increases the level of competition (Jensen, 2004), with older calves pushing small ones out of the feeder stall (Hepola, 2003). Thus, on commercial farms using larger group sizes, an increase in the latency to learn to use the AMF for early-introduced calves could be expected.

Labor for milk feeding chores until calves successfully learned to use the AMF was greater for conventionally introduced calves compared with early-introduced calves after controlling for the effects of season and being tube-fed colostrum. The latter, which was identified as a potential confounder before analysis, had an effect on the labor but did not modify the association between introduction treatment and labor. Whereas calves introduced $<24 \mathrm{~h}$ after birth required more labor to train, assist, and retrain to use the AMF, the amount was still less than the time required to manually feed calves until introduction at d 5. Kung et al. (1997) found that labor required to care for an individually fed and housed calf was 10 times greater than for an AMF-fed, group-housed calf. Kung et al. (1997) also found a much greater difference than we did between treatments (10- vs. 3.7-fold), mainly because in their study labor included not only the feeding of milk and teaching to nurse, but also teaching to consume grain, cleaning, and bedding of pens.

Additionally, we found that labor for milk feeding tasks tended to be greater for calves that were fed colostrum through an esophageal tube at least once, regardless of treatment (no interaction). These tubefed calves were likely less vigorous at birth (Vasseur et al., 2009) and at sucking (Ventorp and Michanek, 1992). Poor vigor probably impaired the expression of neonatal behaviors (e.g., standing and searching for a teat to suck; Barrier et al., 2012).

The present study size was not designed to detect putative differences in the incidence of disease, and we found that the health problems among early- and conventionally introduced calves were similar. The most frequent disease in our study was calf diarrhea, which affected a high but similar proportion of calves in both treatment groups, with a similar median time to onset of $6 \mathrm{~d}$ after introduction to the group. However, the risk of having more severe diarrhea case was significantly greater and the age at the first episode of diarrhea was earlier for early-introduced calves relative to calves conventionally introduced at $5 \mathrm{~d}$ of age. Generally, newborn calves are more susceptible to pathogens and their responses to infection are weaker and slower compared with an older animal (Cortese, 2009). In the first 4 d after birth, immune responses (e.g., production of lymphocytes and IFN- $\gamma$ ) are blocked by different immunosuppressive factors contained in colostrum (e.g., cortisol and prostaglandins), making calves even more susceptible during this period (Rajaraman et al., 1997). Reflecting practice on commercial farms, we noted a range of 2 to $3 \mathrm{wk}$ in the ages of calves in a pen. This is a risk factor for transmission of pathogens from older calves to younger ones, especially those newly arrived in the pen. Whereas the time from introduction to the group pen to onset of diarrhea was not different between our treatments, our observation that the severity of diarrhea was greater among early-introduced calves is consistent with younger animals having less resilience in the face of a pathogenic challenge.

We did not evaluate farm labor related to time spent treating sick calves; however, the duration of treatment 
of calves with severe diarrhea in the present study ( 5.7 $\pm 1.8 \mathrm{~d}$ ) could potentially represent an increase in labor costs when introducing calves $<24 \mathrm{~h}$ after birth due to their higher risk of having severe diarrhea. In addition to the potential increase in labor costs, having diarrhea earlier in life has been found to be a risk factor for bovine respiratory disease after 3 mo of age (Svensson et al., 2006) and calf mortality (Perez et al., 1990; Sivula et al., 1996).

The incidence of diarrhea in our study $(82 \%)$ was higher than the prevalence reported on commercial dairy farms using AMF (23\%; Medrano-Galarza et al., 2018). This high incidence may have been due to crosscontamination of pens with Cryptosporidium parvum, which was detected in fecal samples of 2 severely ill calves. In addition, we used a continuous flow stocking approach, and the prevalence of diarrhea has been found to be at least twice as high for continuous flow versus an all-in/all-out stocking approach (Pedersen et al., 2009) due to a decreased ability to disinfect the pens. Concerning the external validity of our results, the lack of differences between ages of introduction in the risk of having diarrhea could differ from a situation in which the incidence of diarrhea was lower. A reduced load of pathogens in the environment could perhaps result in only more susceptible calves having clinical disease (Cho and Yoon, 2014). On the other hand, the results regarding the higher risk of having severe (vs. mild) diarrhea among early-introduced calves could be generalized to commercial farms, because the severity of diarrhea cases is likely to be linked to calves exposed to pathogens at an early age (as discussed above).

The age of introduction influenced daily milk intake only during the first week of life, with early-introduced calves consuming less milk than conventionally introduced calves. These differences in milk intake, especially on d 3 and 4 (Figure 3), likely resulted from a combination of factors related to the feeding method and the age at training to use the AMF. During this period, conventionally introduced calves were bottle-fed, whereas early-introduced calves were in the training process to use the AMF. Overall, the training of calves to use the AMF was a smooth process, but based on the quantity of milk consumed during the first training session (1.2 vs. $2.6 \mathrm{~L}$ for early- and conventionally introduced calves, respectively) and the differences in intake during those first days of life, we inferred that very young calves were less successful at drinking from the AMF than calves being fed through a bottle. Jensen (2007) also found differences in milk intake between calves introduced to an AMF in a group pen at 6 versus $14 \mathrm{~d}$ of age, although they compared intake by days in the group and not by days of age. In the present study, once learning was achieved, we found no differences in milk intake, and overall milk intake from birth to weaning did not differ. This compensation might have been possible due to the fact that calves in this experiment were allowed to drink milk ad libitum, which allowed them to gradually increase their milk consumption, especially during the first 2 wk of the ad libitum stage, until reaching their maximum intake. This feeding pattern has been previously shown in calves fed high milk allowances (Borderas et al., 2009).

Average daily gain across the milk feeding period was not affected by age of introduction in the present study. Similarly, Svensson and Liberg (2006) did not find any effect of age of introduction (i.e., $<8,>8$ but $\leq 12,<12$ but $\leq 19$, or $>19$ d of age) on growth rate. However, we found that ADG was negatively affected when calves, regardless of treatment, experienced severe diarrhea. Likewise, Donovan et al. (1998) found that as diarrhea became more severe (i.e., as number of treatment days increased), the weight gain from birth to 6 mo of age decreased.

We also found that as the time to successfully learn to use the AMF increased, ADG at $30 \mathrm{~d}$ of age, but not later, decreased. Milk intake is positively associated with ADG (Miller-Cushon et al., 2013); thus, calves that took longer to successfully learn to drink milk from the AMF consumed less milk during those first days after introduction, affecting weight gain during the first mo of life. Fujiwara et al. (2014) found a negative correlation between the latency to first voluntary milk intake from the AMF and milk intake during the first week in the group pen and a tendency with lower ADG.

A single person was used as the only caregiver in charge of feeding and training all calves enrolled in our study. Although having a single caregiver reduced variation we might have expected if multiple caretakers were involved, this could limit the generalizability of the results. On commercial farms more than 1 person might be in charge of the calves, and they could differ in methods of feeding and training, patience in handling calves, and time available for calf care compared with other farm chores. Because a single person was used to feed and train calves, blinding to treatment group was not possible. This lack of blinding could, in principle, have led to some detection bias. However, farm staff and veterinarians of the research center were blinded to treatment group; therefore, the management of individual and group pens and diagnosis and treatment for disease was the same for all calves enrolled in the study.

We emphasize that the current study was not designed to detect differences in disease incidence; thus, the association we found of treatment with severity of diarrhea should be explored in larger studies with sufficient power to test the hypothesis. Another limitation 
of our study was that labor assessment was only focused on milk feeding tasks and did not consider labor related to treating sick calves. Thus, reductions in labor when using early introduction found in our study might be diminished by the potential increase in labor due to more severe cases of diarrhea among early-introduced calves. In addition, the generalizability of our results is limited to farms using continuous flow housing, which is known to have a higher prevalence of diseases compared with stable groups (all-in/all-out; Pedersen et al., 2009).

\section{CONCLUSIONS}

Under a continuous flow stocking approach for raising calves in groups with AMF, calves introduced to the group pen (group size of approximately 7 calves per group) $<24 \mathrm{~h}$ after birth required more assistance to use the AMF and took longer to achieve independent use of the feeder than calves introduced at $5 \mathrm{~d}$ of age. This longer latency to learn to use the AMF did not entail an increase in labor for milk feeding, as calves introduced at $5 \mathrm{~d}$ of age required more labor due to the chores involved with manual milk feeding for $4 \mathrm{~d}$. Age of introduction did not affect ADG nor the risk of diarrhea, but early-introduced calves had onset of diarrhea at a younger age and a greater risk of severe diarrhea. Our results show that introduction to group housing with AMF as early as the first day after birth may be a viable option to reduce labor requirements related to milk feeding tasks without affecting calf growth. However, the health risks and the labor for treating sick calves require more investigation before this practice can be recommended.

\section{ACKNOWLEDGMENTS}

This research was funded by Dairy Farmers of Canada (Ottawa, ON, Canada) as part of the Dairy Research Cluster 2 program and the Ontario Ministry of Agriculture, Food, and Rural Affairs (OMAFRA; Guelph, ON, Canada). The first author also thanks the Administrative Department of Science, Technology and Innovation - Colciencias (Bogota, Cundinamarca, Colombia) for the $\mathrm{PhD}$ scholarship granted. The authors also thank Laura Wright, Joe Parkison, Jeff Mcfarlane, and the staff at the University of Guelph Dairy Research and Innovation Center (Elora, ON, Canada) for their help and contributions to this work. Special thanks to Larissa Martins (Universidade de São Paulo, Pirassununga, SP, Brazil) and Pauline Denis (Agro Campus Ouest, Rennes, France) for their invaluable help during the data collection.

\section{REFERENCES}

Abramson, J. H. 2011. WINPEPI updated: Computer programs for epidemiologists, and their teaching potential. Epidemiol. Perspect. Innov. 8:1.

Barrier, A. C., E. Ruelle, M. J. Haskell, and C. M. Dwyer. 2012. Effect of a difficult calving on the vigour of the calf, the onset of maternal behaviour, and some behavioural indicators of pain in the dam. Prev. Vet. Med. 103:248-256. https://doi.org/10.1016/j prevetmed.2011.09.001.

Borderas, T. F., A. M. B. de Passillé, and J. Rushen. 2009. Feeding behavior of calves fed small or large amounts of milk. J. Dairy Sci. 92:2843-2852. https://doi.org/10.3168/jds.2008-1886.

Cho, Y. I., and K. Yoon. 2014. An overview of calf diarrhea - infectious etiology, diagnosis, and intervention. J. Vet. Sci. 15:1-17. https://doi.org/10.4142/jvs.2014.15.1.1.

Cortese, V. S. 2009. Neonatal immunology. Vet. Clin. North Am. Food Anim. Pract. 25:221-227. https://doi.org/10.1016/j.cvfa.2008.10 .003 .

Dohoo, I., W. Martin, and H. Stryhn. 2009. Veterinary Epidemiologic Research. VER, Inc. Charlottetown, Prince Edward Island, Canada.

Donovan, G. A., I. R. Dohoo, D. M. Montgomery, and L. Bennett. 1998. Calf and disease factors affecting growth in female Holstein calves in Florida, USA. Prev. Vet. Med. 33:1-10. https://doi.org/ 10.1016/S0167-5877(97)00059-7.

Duve, L., and M. B. Jensen. 2011. The level of social contact affects social behaviours in pre-weaned dairy calves. Appl. Anim. Behav. Sci. 135:34-43. https://doi.org/10.1016/j.applanim.2011.08.014.

Fujiwara, M., J. Rushen, and M. de Passillé. 2014. Dairy calves' adaptation to group housing with automated milk feeders. Appl. Anim. Behav. Sci. 158:1-7. https://doi.org/10.1016/j.applanim.2014.06 .011 .

Hepola, H. 2003. Milk feeding systems for dairy calves in groups: Effects on feeding intake, health and growth. Appl. Anim. Behav. Sci. 80:233-243. https://doi.org/10.1016/S0168-1591(02)00214-9.

Jensen, M. B. 2004. Computer-controlled milk feeding of dairy calves: The effects of number of calves per feeder and number of milk portions on use of feeder and social behavior. J. Dairy Sci. 87:34283438. https://doi.org/10.3168/jds.S0022-0302(04)73478-5.

Jensen, M. B. 2007. Age at introduction to the group affects dairy calves' use of a computer-controlled milk feeder. Appl. Anim. Behav. Sci. 107:22-31. https://doi.org/10.1016/j.applanim.2006.09 .017 .

Jorgensen, M. W., A. Adams-Progar, A. M. de Passille, J. Rushen, S. M. Godden, H. Chester-Jones, and M. I. Endres. 2017. Factors associated with dairy calf health in automated feeding systems in the Upper Midwest United States. J. Dairy Sci. 100:5675-5686. https://doi.org/10.3168/jds.2016-12501.

Kung, L., Jr., S. Demarco, L. N. Siebenson, E. Joyner, G. F. W. Haenlein, and R. M. Morris. 1997. An evaluation of two management systems for rearing calves fed milk replacer. J. Dairy Sci. 80:2529-2533. https://doi.org/10.3168/jds.S0022-0302(97)76206 -4 .

McGuirk, S. M. 2008. Disease management of dairy calves and heifers. Vet. Clin. North Am. Food Anim. Pract. 24:139-153. https://doi .org/10.1016/j.cvfa.2007.10.003.

Medrano-Galarza, C., S. J. LeBlanc, T. J. DeVries, A. Jones-Bitton, J. Rushen, A. M. de Passillé, and D. B. Haley. 2017a. A survey of dairy calf management practices among farms using manual and automated milk feeding systems in Canada. J. Dairy Sci. 100:6872-6884. https://doi.org/10.3168/jds.2016-12273.

Medrano-Galarza, C., S. J. LeBlanc, A. Jones-Bitton, T. J. DeVries, J. Rushen, A. M. de Passillé, M. I. Endres, and D. B. Haley. 2018. Associations between management practices and within-pen prevalence of calf diarrhea and respiratory disease on dairy farms using automated milk feeders. J. Dairy Sci. 101:2293-2308. https://doi .org/10.3168/jds.2017-13733.

Miller-Cushon, E. K., R. Bergeron, E. Leslie, and J. DeVries. 2013. Effect of milk feeding level on development of feeding behavior in 
dairy calves. J. Dairy Sci. 96:551-564. https://doi.org/10.3168/jds .2012-5937.

Perez, E., J. P. T. M. Noordhuizen, L. A. Van Wuijkhuise, and E. N. Stassen. 1990. Management factors related to calf morbidity and mortality rates. Livest. Prod. Sci. 25:79-93. https://doi.org/ 10.1016/0301-6226(90)90043-6.

Pedersen, R. E., J. T. Sørensen, F. Skjøthc, J. Hindhede, and T. R. Nielsen. 2009. How milk-fed dairy calves perform in stable versus dynamic groups. Livest. Sci. 121:215-218. https://doi.org/10 $.1016 /$ j.livsci.2008.06.007.

Rajaraman, V., B. J. Nonnecke, and R. L. Horst. 1997. Effects of replacement of native fat in colostrum and milk with coconut oil on fat-soluble vitamins in serum and immune function in calves. J. Dairy Sci. 80:2380-2390. https://doi.org/10.3168/jds.S0022 -0302(97)76189-7.

SAS. 2017. The GENMOD Procedure. SAS/STAT(R) User's Guide. Accessed Oct. 21, 2017. https://support.sas.com/documentation/ cdl/en/statug/63347/HTML/default/viewer.htm\#statug_genmod _sect004.htm.

Sivula, N. J., T. R. Ames, W. E. Marsh, and R. E. Werdin. 1996. Descriptive epidemiology of morbidity and mortality in Minnesota dairy heifer calves. Prev. Vet. Med. 27:155-171. https://doi.org/10 .1016/0167-5877(95)01000-9.

Svensson, C., J. Hultgren, and P. A. Oltenacu. 2006. Morbidity in 3-7-month-old dairy calves in south-western Sweden, and risk fac- tors for diarrhea and respiratory disease. Prev. Vet. Med. 74:162179. https://doi.org/10.1016/j.prevetmed.2005.11.008.

Svensson, C., and P. Liberg. 2006. The effect of group size on health and growth rate of Swedish dairy calves housed in pens with automatic milk-feeders. Prev. Vet. Med. 73:43-53. https://doi.org/10 .1016/j.prevetmed.2005.08.021.

Svensson, C., K. Lundborg, U. Emanuelson, and S.-O. Olson. 2003. Morbidity in Swedish dairy calves from birth to 90 days of age and individual calf-level risk factors for infectious diseases. Prev. Vet. Med. 58:179-197. https://doi.org/10.1016/S0167-5877(03)00046 $-1$.

Vasseur, E., J. Rushen, and A. M. de Passillé. 2009. Does a calf's motivation to ingest colostrum depend on time since birth, calf vigor, or provision of heat? J. Dairy Sci. 92:3915-3921. https://doi.org/ $10.3168 /$ jds.2008-1823.

Ventorp, M., and P. Michanek. 1992. The importance of udder and teat conformation for teat seeking by the newborn calf. J. Dairy Sci. 75:262-268. https://doi.org/10.3168/jds.S0022-0302(92)77761 -3 .

Windeyer, M. C., K. E. Leslie, S. M. Godden, D. C. Hodgins, K. D. Lissemore, and S. J. LeBlanc. 2014. Factors associated with morbidity, mortality, and growth of dairy heifer calves up to 3 months of age. Prev. Vet. Med. 113:231-240. https://doi.org/10.1016/j .prevetmed.2013.10.019. 